\title{
Animal Models for Vascular Tissue-Engineering
}

\author{
Daniel D. Swartz ${ }^{1,4, \S}$ and Stelios T. Andreadis $2,3,4, \S$ \\ ${ }^{1}$ Department of Pediatrics, University at Buffalo, The State University of New York, Amherst, NY \\ $14260-4200$ \\ ${ }^{2}$ Bioengineering Laboratory, Department of Chemical and Biological Engineering, University at \\ Buffalo, The State University of New York, Amherst, NY 14260-4200
}

${ }^{3}$ Department of Biomedical Engineering, University at Buffalo, The State University of New York, Amherst, NY 14260-4200

${ }^{4}$ Center of Excellence in Bioinformatics and Life Sciences, Buffalo, NY 14203

\begin{abstract}
Due to rise in cardiovascular disease throughout the world, there is increasing demand for small diameter blood vessels as replacement grafts. The present review focuses on the animal models that have been used to test small-diameter TEVs with emphasis on the attributes of each model. Small animal models are used to test short-term patency and address mechanistic hypotheses; and large, pre-clinical animal models are employed to test long-term patency, remodeling and function in an environment mimicking human physiology. We also discuss recent clinical trials that employed laboratory fabricated TEVs and showed very promising results. Ultimately, animal models provide a testing platform for optimizing vascular grafts before clinical use in patients without suitable autologous vessels.
\end{abstract}

\section{Keywords}

Vascular grafts; tissue engineering; regenerative medicine; animal models; cardiovascular physiology

\section{Introduction}

\section{Clinical Necessity}

Due to rise in cardiovascular disease throughout the world, there is increasing demand for small diameter blood vessels as replacement grafts. In 2006 heart disease was responsible for more than 600,000 deaths, half of which were caused by coronary heart disease. Notably, 400,000 surgical bypass operations were performed in the same year, highlighting the need for a small diameter arterial substitute. To date, saphenous veins, internal mammary and

\footnotetext{
(C) 2013 Elsevier Ltd. All rights reserved.

§Address for all Correspondence: Daniel D. Swartz, Ph.D., Assistant Professor, Department of Pediatrics, and Center of Excellence in Bioinformatics and Life Sciences, University at Buffalo, The State University of New York, Buffalo, NY 14222, Tel: (716) 829-2536, swartzda@ buffalo.edu or Stelios Andreadis, Ph.D., Professor, Bioengineering Laboratory, 908 Furnas Hall, Department of Chemical and Biological Engineering, Department of Biomedical Engineering, and Center of Excellence in Bioinformatics and Life Sciences, University at Buffalo, The State University of New York, Amherst, NY 14260-4200, Tel: (716) 645-1202, Fax: (716) 645-3822, sandread@buffalo.edu.

Publisher's Disclaimer: This is a PDF file of an unedited manuscript that has been accepted for publication. As a service to our customers we are providing this early version of the manuscript. The manuscript will undergo copyediting, typesetting, and review of the resulting proof before it is published in its final citable form. Please note that during the production process errors may be discovered which could affect the content, and all legal disclaimers that apply to the journal pertain.
} 
radial arteries are considered the golden standard for replacement of diseased coronary arteries. However, autologous vessels are unsuitable in many patients presenting with vascular disease due to small size, varicosities, anatomic variation, previous removal, or other abnormalities. Vessel quality is a critical factor in the long-term patency and function of vascular grafting procedures, as well, vessel harvest is time-consuming and a major contributor to postoperative morbidity [1]. Therefore, the limited graft availability, especially in elderly patients, together with the increased 10 year failure rate of venous grafts suggest that alternative strategies are urgently needed [2]. Although synthetic materials such as Darcon and polytetrafluorethlene can be used to substitute large diameter vessels, thrombogenicity and poor elasticity make them inappropriate for engineering small diameter vessels [3].

Tissue engineering approaches were developed to bypass the drawbacks of synthetic materials [4-13]. Technological advances in biomaterials and bioreactor technologies have produced strong vascular grafts that can be optimally pre-conditioned to withstand the mechanical microenvironment of arterial circulation [9,11,14] (Fig. 1). However, two major issues remain: cell source and animal models to test implantability of tissue engineered vessels (TEVs) prepared from different cells and materials.

\section{Cell sourcing}

Autologous EC and SMC have been successfully introduced into engineered grafts, but their isolation requires patient biopsies. Moreover expansion of those cells to the large numbers required for engineering TEVs is limited by their low proliferation potential, especially when originating from elderly patients [15]. Terminally differentiated vascular cells isolated from aged patients exhibited reduced functionality and decreased extracellular matrix remodeling resulting in failing grafts $[16,17]$. On the other hand stem cells are promising cell sources that have the potential to overcome the limitations of mature and terminally differentiated cells. Stem cells, adult or induced pluripotent stem cells (iPSC), have increased proliferation and broad differentiation capacity, making them ideally suited for regenerative medicine. In particular, adult mesenchymal stem cells (MSC) have been widely investigated for clinical use to treat a variety of degenerative diseases and more than 200 clinical trials have been initiated to date using MSC as functional therapeutics [18].

However, similar to terminally differentiated cells, donor aging and culture senescence appears to affect the proliferation and differentiation potential of stem cells as well $[19,20]$. Our laboratory reported that the proliferation capacity, the myogenic differentiation potential and the ability to generate force were greatly diminished with donor aging [21]. Notably, we also showed that ectopic expression of Nanog reversed the proliferation and myogenic differentiation potential of bone marrow-derived MSC (BM-MSC) from adult donors to a similar level as that of their neonatal counterparts [22]. In addition, we developed an efficient stage-wise strategy that enabled hiPSC differentiation into contractile SMC through an intermediate population of clonogenic and multipotent MSC, suggesting that this may be an alternative strategy to overcome the effects of donor aging in adult stem cells [23]. Finally, our laboratory discovered a novel source of MSC, namely hair follicle derived (HF)MSC, which showed high proliferation and multi-lineage differentiation potential as well as higher resistance to culture senescence as compared to bone marrow derived MSC [24-27]. The use of stem cells for cardiovascular tissue engineering and regenerative medicine is a topic of intense scientific interest and has been reviewed recently [28].

\section{Animal models}

In addition to cell sourcing, pre-clinical assessment of TEVs using appropriate animal models is essential to determine the clinical potential of engineered tissues. There are 
several variables that need to be considered when selecting an appropriate animal model, including thrombogenicity, immunogenicity, size of vascular graft, implantation site and the specific clinical need that is being assessed. The present review focuses on the animal models that have been used to test small-diameter TEVs with emphasis on the attributes of each model.

\section{Animal Model Selection Criteria}

During the course of TEV development there are many criteria that are utilized in the assessment of clinical potential. Each of these criteria may be best analyzed in different experimental settings. The optimal target criteria would obviously be those that match the naturally occurring physiology of the native blood vessel that is being substituted. As normal human physiology is difficult to mimic, there have been minimally acceptable criteria established and published to guide the development of vascular substitutes [29,30]. These include the ability to be sterilized, reproducibility, acceptable cost, low porosity, implantability (anastomosis, site plasticity, and kink resistance), lack of immunogenicity, site-specific strength, and long-term remodeling and function. In addition, it would be necessary for the TEV to be physiologically functional and non-thrombogenic [31]. These criteria can be examined in in-vitro and in-vivo settings. There are no in-vivo models, which are optimal for testing all criteria and hence the need for multiple animal models to optimize testing for specific developmental criteria.

The selection of an appropriate animal model needs to include criteria relevant to the TEV graft such as implantation site, TEV diameter and length, and time frame of implantation. Equally important are criteria relevant to the animal species selected such as cost, availability, ease of handling, animal response to surgical procedure, target vessel diameter and length and target physiology. Optimally, an animal model needs to be selected that meets most of these criteria. It is best to match site and diameter to test hemodynamics and implantability; use longer grafts ( $>4 \mathrm{~cm}$ ) to test patency; type of anastomosis (end-to-end, end-to-side) to test shear stress; or select species that exhibit similar immunogenicity and thrombogenicity mechanisms as those at work in humans. The type of analysis - e.g. serial imaging or monitoring vs. a single measurement at the end of the experiment - is also important in determining the choice of animal model.

Similarity to human physiology is one major factor that is considered when assessing criteria specifically related to translational studies. For example, ovine and non-human primate models show greater similarity to humans in terms of thrombogenicity mechanisms as compared to dogs or pigs. On the other hand, similar to humans, dogs exhibit lack of spontaneous endothelialization of vascular grafts and they tend to be hyperthrombogenic. These two features make the dog model more stringent for TEV testing. In contrast, lack of similarity in vascular dimensions and hemodynamics make small animals like mice and rats poor models for long-term TEV evaluation. However, the plethora of transgenic mice presents a very useful resource to dissect molecular mechanisms related to immune response, remodeling, vascular reactivity and other aspects of graft physiology.

Just as donor age affects the quality of stem cells and the resulting TEVs, the age of recipient animals may affect the microenvironmental factors that are critical for successful grafting and long-term tissue regeneration. To date, little attention has been paid into understanding how the outcome of grating procedures depends on the age of the recipient. Optimal vascular grafting requires integration, remodeling and functionality of the graft, which is highly dependent upon the recipient's regenerative ability, primarily determined by age. It is reasonable to expect that young adults represent an optimal age group of recipients due to high regeneration capacity and relative growth stability. However, if one is to 
consider the "real" clinical environment, it is the elderly who are typically the recipients of vascular grafting procedures and therefore, the age of the recipient should be considered in studies of pre-clinical TEV assessment. Age of the recipient is also critical when considering vascular grafting procedures into children. In this case, the ability of the graft to grow with the patient is of high clinical relevance.

Gender can also be a significant factor, as estrogen/testosterone and pre-puberty/postpuberty are well-documented factors affecting gene expression and cellular function. Also, gender can be used to differentiate between host vs. donor cells, thereby enabling studies to monitor host cell infiltration and track donor cell fate post-implantation. As the concerns of animal rights and limitations on the use of non-human primate increase, the pig and sheep models have become more widely used in recent years. In addition to the ethical considerations, cost is also a factor, making the pig and sheep the models of choice. In the following, we present studies using large and small animals models as well as the few clinical studies that have begun to test tissue-engineered vascular grafts. Table 1 summarizes tissue engineered graft implantation studies that employed large or small animal models.

\section{Large Animal Models}

\section{Non-human primates}

Non-human primates demonstrate considerable similarity to humans in terms of cardiovascular physiology and thrombogenic mechanisms as well as high susceptibility in developing atherosclerosis. Non-human primates, such as baboons, also allow a significant advantage in greater availability of cellular markers, non-invasive imaging technologies, thrombosis evaluation assays, and limited fibrous encapsulation as compared to other large animal models. A recent study by the Niklason group employed this animal model to test the first off-the-shelf TEV that was prepared from allogeneic human vascular smooth muscle cells that were seeded onto a polyglycolic acid (PGA) scaffold and cultured for 7-10 weeks in vitro to allow for significant matrix remodeling and collagen production. At that time, the grafts were decellularized to minimize thrombogenicity and to become amenable to longterm storage. Decellularized TEVs were implanted into a baboon model of arteriovenous access for hemodialysis where they retained their patency and strength for up to 6 months [8]. The ability to store these engineered tissues for several months or longer means that they can be prepared ahead of time and transported as needed, i.e. they become readily available off-the-self human grafts. The success of this pre-clinical model demonstrated that decellularized, off-the-shelf TEVs are a feasible alternative with high clinical potential. However, due to ethical concerns and high cost, the non-human primate model is not the model of choice for the majority of researchers who use other models such as sheep, pig and $\operatorname{dog}$.

\section{Sheep (ovine)and goats (caprine)}

Sheep and goats are large animals that have long necks that allow for easy access and implantation into the carotid artery, a preferred site for TEV assessment. These large animals are ideal for testing TEVs of 4-6 $\mathrm{mm}$ in diameter with blood thrombogenic mechanisms similar to humans. The common carotid artery is long with no major bifurcations and allows easy access to assess waveform pulsatility and patency via ultrasound. The sheep and goats are quickly maturing animals that are amenable to longterm studies due to cost effectiveness, ease of handling and similarities of their cardiovascular physiology with humans.

Swartz and colleagues generated TEVs from ovine SMC and ECs that were embedded in fibrin hydrogels and implanted them into the jugular veins of 12 week-old lambs [13]. These vessels demonstrated excellent remodeling with considerable collagen and elastin 
production demonstrating implantability of fibrin-based TEVs (Fig. 2). In a follow up study our group developed a novel method to isolate smooth muscle cells from bone marrow (BM) derived mesenchymal stem cells using a tissue specific promoter and fluorescence activated cell sorting [12]. TEVs prepared from BM-MSC derived SMC and BM-derived endothelial cells (EC) were implanted into the jugular vein of the same animal model. As early as five weeks post-implantation, BM-derived SMC aligned circumferentially and produced large amounts of collagen. In contrast to previous results with vascular SMC, BM-MSC derived SMC synthesized high amounts of elastin that was organized in a fibrillar network very similar to native vessels (Fig. 2), suggesting that BM-MSC have high potential for development of stem cell therapeutics for treatment of cardiovascular disease. To enable arterial implantation, our group combined the properties of fibrin hydrogel with the mechanical strength of a native biomaterial, small intestinal submucosa (SIS) into a hybrid cylindrical construct that was able to withstand arterial pressure as an arteriovenous shunt and as interpositional graft in the ovine carotid artery [11,32 ]. Using a slightly different approach Koch and colleagues seeded autologous arterial cells onto a fibrin scaffolds that were supported by a polylactide mesh and implanted them interpositionally into the carotid artery of sheep [33]. At 6 months post-implantation, the grafts were patent and showed no signs of thrombosis with EC markers present in the lumen.

In another approach, decellularized arterial ovine scaffolds were seeded with autologous circulating EPCs and after pre-conditioning were implanted as arterio-venous shunts between the jugular vein and carotid artery of sheep [34]. Needle puncture and venous outflow was assessed up to 6 months. TEVs showed stable wall geometry but all grafts eventually developed venous anastomotic stenosis, the primary mode of graft failure. TEVs were also constructed from human amniotic membranes and implanted into the external jugular vein of juvenile sheep, where they remained patent for 48 weeks, and the grafts had no signs of inflammation or fibrosis, intimal hyperplasia, or dilation [35]. Finally, matrix remodeling was assessed in vivo by implantation of TEVs from biodegradable scaffolds of polyglycolic-acid/poly-4-hydroxybutyrate (PGA/P4HB) [36]. Two studies by the same group [36,37] demonstrated that these TEV s possessed the ability to grow with the recipients, a finding of high clinical relevance when grafting into children. Collectively, these studies showed that the ovine model is an excellent pre-clinical model to evaluate the short-term patency and long-term remodeling of tissue engineered vascular grafts.

\section{Pigs (Porcine)}

Pigs also resemble vascular human anatomy and physiology and they are used extensively for assessing cardiovascular devices, and in studies of vascular injury and restenosis. However, pigs mount an extensive immune response to transplants and their rapid growth presents difficulties in handling of adult animals, thereby restricting their use to short-term studies. For these reasons, the miniature pig has gained popularity in recent years as a model system for TEV assessment.

In a pioneering study Niklason and colleagues employed polyglycolic acid (PGA) as a scaffold for engineering TEVs that were subjected to pulsatile flow for 8 weeks in vitro before implantation into a pig model [4]. This was the first study to demonstrate short-term patency ( 24 days), establishing the feasibility of implanting tissue engineered vascular grafts. In a more recent study the same group engineered PGA-based TEVs that were later decellularized, leaving behind the mechanically robust extracellular matrix of the graft wall. The presence of autologous EC or EPC in the lumen promoted short-term (30 days) patency in pigs, demonstrating the feasibility of readily available decellularized TEVs for implantation [38]. Grafts of small intestinal submucosa were also implanted into the thoracic superior vena cava of piglets to assess their potential to grow with the animals over a 3month period. In this time, the diameter almost doubled and the length increased by $50 \%$, 
demonstrating the potential of these TEVs as a cardiovascular substitutes in growing children [39].

\section{Dog (canine)}

Dogs are widely used for a variety of cardiovascular applications. They exhibit significant differences in thrombogenic mechanisms and vascular viscoelastic properties as compared to humans, ovine and non-human primate models. In addition, their marked immune response to the implants poses restrictions to the use of dogs in long-term patency studies. The dog however, provides a greater selection of diameter and implantation site options. Large diameter vessels can be implanted into the thoracic or abdominal aorta, while small diameter (3-5 $\mathrm{mm}$ ) vessels can be implanted interpositionally into the common carotid and aortoiliac arteries.

Dogs have been used for testing the efficacy and patency of TEVs that were engineered with a variety of synthetic and biological matrices seeded with autologous cells derived from adipose tissue, epithelium, smooth muscle, and small intestinal sub mucosa. Watanabe and colleagues used biodegradable scaffolds that were seeded with mixed cells from the femoral veins of mongrel dogs [40]. After one week, the TEVs were placed interpositionally into the inferior vena cavas (IVCs) of the same dogs. Upon angiographic imaging, there was no evidence of stenosis or dilatation and the grafts remained patent. L'Heureux and colleagues utilized a scaffold-free method, in which cell sheets of human fibroblasts were rolled into cylindrical TEVs that exhibited very good mechanical properties enabling implantation as interposition grafts into the femoral artery of mongrel dogs. These xenogeneic grafts were not seeded with luminal EC and maintained a patency of 50\% at 1 week after implantation [6]. In another study from the Niklason group, canine smooth muscle cells were seeded onto a polyglycolic scaffold and after 7-10 weeks of culture TEVs were decellularized to create an off-the-shelf product. Then the grafts were luminally seeded with autologous endothelial cells and implanted into the left anterior descending coronary artery or as carotid artery bypass grafts in a dog animal model for up to 12 months. The grafts demonstrated high patency rates (83\%) and resisted calcification and intimal hyperplasia [8]. In a similar approach, heparin-coated, decellularized dog carotid arteries were seeded with autologous circulating EPCs and implanted into the carotid arteries of donor dogs. At 3 months, the grafts were mostly patent and exhibited minimal intimal hyperplasia [41].

\section{Small Animal Models}

\section{Rabbits (leporine)}

Rabbits are the optimal small animal model for studying small diameter (1-4mm) vascular grafts. The rabbit vascular physiology resembles that of humans in several aspects, more so than the rat, including thrombogenicity mechanisms, patency and endothelialization rates. The rabbit is the largest of the small animal models that enables bilateral interposition implantation of longer TEVs into aorta, carotid or femoral arteries and there are more noninvasive techniques available to evaluate the grafts, such as, palpation of ipsilateral central ear artery or by Doppler ultrasound $[42,43]$. On the other hand, long-term patency studies are difficult to perform in the rabbit due to its size and vascular physiology. For these reasons, rabbits can be employed to assess short-term efficacy and safety of implanted TEVs and screen multiple conditions before moving onto large animal models.

\section{Rats and mice (murine)}

Rats and mice can only be used to study very small diameter $(1-2 \mathrm{~mm})$ and very short length $(1 \mathrm{~cm})$ TEVs. These small rodents allow for high throughput experimentation as they are more cost effective and require less maintenance. A major advantage is the utilization of 
specific transgenic models to further study integration and developmental aspects of TEV implantations. However, the cardiovascular physiology and thrombogenicity mechanisms are not as similar to humans as some of the large animal models.

TEVs from different biomaterials such as a polysaccharide gel [44] or decellularized rat aortas [45] have been tested in rats with various degrees of success. A severe combined immunodeficiency (SCID) mouse model was developed by Lopez-Soler and colleagues for testing xenogeneic TEVs [46]. Small diameter aortic interposition grafts were made from decellularized ovine arterial tissue. These grafts were implanted interpositionally as infrarenal aortic grafts and demonstrated very good patency from 1 to 35 days. This model decreased the complications of immune reaction and the higher cost associated with large animal models. Others used a CD11b-diptheria toxin receptor (DTR) transgenic mouse model to study the role of macrophages in TEV stenosis [47]. They found that the transition from M1 to M2 macrophage phenotype correlated with increased graft stenosis, which was eliminated significantly in DTR mice as well as in mice in which macrophages were depleted by chemical treatment. On the other hand, lack of macrophages inhibited infiltration of endothelial and smooth muscle cells into the grafts and eliminated collagen deposition and long-term remodeling, suggesting that macrophage infiltration is critical for successful TEV remodeling. It would be interesting to test some of these findings in large animals models and ultimately in humans.

\section{Clinical Studies}

Human clinical trials with TEVs are still in their early stages. Preclinical evaluation studies utilizing large animal models may predict the success of tissue engineered vascular grafts, however, extrapolating the results to humans is difficult. Clinical trials should be performed with long-term clinical evaluation to determine the integration, patency and function of tissue engineered vascular grafts. In a case report, the pulmonary artery was successfully reconstructed in a four-year-old girl and remained patent with increasing diameter over time [48]. A clinical application also conducted by Shin'oka and collaborators in 2001 using TEVs made of a biodegradable synthetic scaffold (copolymer of 1-lactide and -caprolactone (50:50)), seeded with autologous bone marrow cells and implanted into 42 patients as extracardiac total cavopulmonary connections or tissue engineered patches (low pressure environment). The patients were followed for up to 32 months and showed normal vascular function with no thrombosis, stenosis, or obstruction [49]. In a long-term follow up (mean follow up time 5.8 years) with clinical and radiologic surveillance of 25 patients there was no indication of aneurysm formation, graft rupture, infection or ectopic calcification [50].

Autologous fibroblast based tissue engineered blood vessels have been used for adult human peripheral arterial vascularization and clinical results have been very promising [51,52]. Specifically, arteriovenous shunt grafts were engineered using the rolled sheet method and implanted into ten patients with end stage renal disease. The grafts were followed up for 6 months and demonstrated $78 \%$ patency even after repeated puncturing for hemodialysis [52]. Testing of TEVs in humans is an exciting success for vascular tissue engineering that will hopefully pave future investment in the development of cellular therapies and their translation to the clinic.

\section{Summary-Conclusions}

There are no absolute ideal animal models or international consensus on standards associated with the development and testing of TEVs. The lack of standardized models makes it difficult to compare results among investigators. In order to best evaluate the implantation of TEVs assessed in such a variety of animal models require optimal model selection and use of proper internal controls. Some critical aspects that need to be considered 
in choosing the correct animal model include the species, strain, size, relevant aspects of cardiovascular physiology, and site of implantation. It is also important to use suitable controls (e.g. re-anastomosed native vessels), preferably in the same animal and same position.

Selection of an animal must be based on its suitability to examine the TEV property under investigation, e.g. thrombogenicity, cell infiltration or the capacity to grow with the host. The best animal models to examine certain TEV features are summarized in Table 2. Small animal models are more cost-effective and amenable to high throughput experimentation. Use of transgenic and knock in mice and rats may be very useful in addressing mechanistic questions related to vascular implantation. However, studies that aim at obtaining preclinical data to establish the clinical potential of TEVs must employ large animal models that resemble human anatomy and physiology more closely. These may include implantation of site-specific, full-size grafts and long-term studies of vascular integration and function. Ultimately, it would be optimal to use immune-controlled, large animal models for testing of human TEVs in translational pre-clinical studies.

\section{References}

1. Ricotta, J. Vascular Conduits. In: RBR, editor. Vascular Surgery. Elsevier Saunders; 2005.

2. Gaudino M, Cellini C, Pragliola C, Trani C, Burzotta F, Schiavoni G, Nasso G, Possati G. Arterial versus venous bypass grafts in patients with in-stent restenosis. Circulation. 2005; 112:I265-269. [PubMed: 16159829]

3. Conte MS. The ideal small arterial substitute: a search for the Holy Grail? FASEB J. 1998; 12:4345. [PubMed: 9438409]

*4. Niklason LE, Gao J, Abbott WM, Hirschi KK, Houser S, Marini R, Langer R. Functional arteries grown in vitro. Science. 1999; 284:489-493. The first demonstration of functional artery engineered in vitro. [PubMed: 10205057]

5. L'Heureux N, Paquet S, Labbe R, Germain L, Auger FA. A completely biological tissue-engineered human blood vessel. FASEB J. 1998; 12:47-56. [PubMed: 9438410]

*6. L’Heureux N, Dusserre N, Konig G, Victor B, Keire P, Wight TN, Chronos NA, Kyles AE, Gregory CR, Hoyt G, et al. Human tissue-engineered blood vessels for adult arterial revascularization. Nat Med. 2006; 12:361-365. First demonstration of implantable blood vessel engineered with the cell sheet method. [PubMed: 16491087]

7. Roh JD, Sawh-Martinez R, Brennan MP, Jay SM, Devine L, Rao DA, Yi T, Mirensky TL, Nalbandian A, Udelsman B, et al. Tissue-engineered vascular grafts transform into mature blood vessels via an inflammation-mediated process of vascular remodeling. Proc Natl Acad Sci U S A. 2010; 107:4669-4674. [PubMed: 20207947]

8. Dahl SL, Kypson AP, Lawson JH, Blum JL, Strader JT, Li Y, Manson RJ, Tente WE, DiBernardo L, Hensley MT, et al. Readily available tissue-engineered vascular grafts. Sci Transl Med. 2011; 3:68ra69.

9. Syedain ZH, Meier LA, Bjork JW, Lee A, Tranquillo RT. Implantable arterial grafts from human fibroblasts and fibrin using a multi-graft pulsed flow-stretch bioreactor with noninvasive strength monitoring. Biomaterials. 2011; 32:714-722. [PubMed: 20934214]

10. Isenberg BC, Williams C, Tranquillo RT. Small-diameter artificial arteries engineered in vitro. Circ Res. 2006; 98:25-35. [PubMed: 16397155]

11. Peng H, Schlaich EM, Row S, Andreadis ST, Swartz DD. A novel ovine ex vivo arteriovenous shunt model to test vascular implantability. Cells Tissues Organs. 2012; 195:108-121. [PubMed: 22005667]

12. Liu JY, Swartz DD, Peng HF, Gugino SF, Russell JA, Andreadis ST. Functional tissue-engineered blood vessels from bone marrow progenitor cells. Cardiovasc Res. 2007; 75:618-628. [PubMed: 17512920]

*13. Swartz DD, Russell JA, Andreadis ST. Engineering of fibrin-based functional and implantable small-diameter blood vessels. Am J Physiol Heart Circ Physiol. 2005; 288:H1451-1460. First 
demonstration of functional and impantable blood vessels from fibrin hydrogels. [PubMed: 15486037]

14. Gong Z, Niklason LE. Small-diameter human vessel wall engineered from bone marrow-derived mesenchymal stem cells (hMSCs). FASEB J. 2008; 22:1635-1648. [PubMed: 18199698]

15. Bierman EL. The effect of donor age on the in vitro life span of cultured human arterial smoothmuscle cells. In Vitro. 1978; 14:951-955. [PubMed: 730203]

16. Poh M, Boyer M, Solan A, Dahl SL, Pedrotty D, Banik SS, McKee JA, Klinger RY, Counter CM, Niklason LE. Blood vessels engineered from human cells. Lancet. 2005; 365:2122-2124. [PubMed: 15964449]

17. Seruya M, Shah A, Pedrotty D, du Laney T, Melgiri R, McKee JA, Young HE, Niklason LE. Clonal population of adult stem cells: life span and differentiation potential. Cell Transplant. 2004; 13:93-101. [PubMed: 15129755]

18. Karp JM, Leng Teo GS. Mesenchymal stem cell homing: the devil is in the details. Cell Stem Cell. 2009; 4:206-216. [PubMed: 19265660]

19. Zhou S, Greenberger JS, Epperly MW, Goff JP, Adler C, Leboff MS, Glowacki J. Age-related intrinsic changes in human bone-marrow-derived mesenchymal stem cells and their differentiation to osteoblasts. Aging Cell. 2008; 7:335-343. [PubMed: 18248663]

20. Baxter MA, Wynn RF, Jowitt SN, Wraith JE, Fairbairn LJ, Bellantuono I. Study of telomere length reveals rapid aging of human marrow stromal cells following in vitro expansion. Stem Cells. 2004; 22:675-682. [PubMed: 15342932]

21. Han J, Liu JY, Swartz DD, Andreadis ST. Molecular and functional effects of organismal ageing on smooth muscle cells derived from bone marrow mesenchymal stem cells. Cardiovasc Res. 2010; 87:147-155. [PubMed: 20097675]

**22. Han J, Mistriotis P, Lei P, Wang D, Liu S, Andreadis ST. Nanog reverses the effects of organismal aging on mesenchymal stem cell proliferation and myogenic differentiation potential. Stem Cells. 2012; 30:2746-2759. This paper demonstrates the use of a pluripotency factor, Nanog to reverse the effects of organismal aging on the proliferation and myogenic differentiation potential of MSC into SMC. [PubMed: 22949105]

23. Bajpai VK, Mistriotis P, Loh YH, Daley GQ, Andreadis ST. Functional vascular smooth muscle cells derived from human induced pluripotent stem cells via mesenchymal stem cell intermediates. Cardiovasc Res. 2012; 96:391-400. [PubMed: 22941255]

24. Liu JY, Peng HF, Andreadis ST. Contractile smooth muscle cells derived from hair-follicle stem cells. Cardiovasc Res. 2008; 79:24-33. [PubMed: 18316325]

25. Liu JY, Peng HF, Gopinath S, Tian J, Andreadis ST. Derivation of functional smooth muscle cells from multipotent human hair follicle mesenchymal stem cells. Tissue Eng Part A. 2010; 16:25532564. [PubMed: 20236033]

26. Bajpai VK, Mistriotis P, Andreadis ST. Clonal multipotency and effect of long-term in vitro expansion on differentiation potential of human hair follicle derived mesenchymal stem cells. Stem Cell Res. 2012; 8:74-84. [PubMed: 22099022]

27. Koobatian M, Liang MS, Swartz DD, Andreadis ST. Differential effects of pulsatile pressure on contractile function of neonatal vs. adult mesenchymal stem cells. 2013 In preparation.

28. Bajpai VK, Andreadis ST. Stem cell sources for vascular tissue engineering and regeneration. Tissue Eng Part B Rev. 2012; 18:405-425. [PubMed: 22571595]

29. Standardization IOf. Cardiovascular implants-tubular prostheses. 1998.

30. Standard, AN., editor. Association for the Advancement of Medical Instrumentation. Cardiovascular implants-vascular graft prostheses. 2000.

31. Abbott WM, Callow A, Moore W, Rutherford R, Veith F, Weinberg S. Evaluation and performance standards for arterial prostheses. J Vasc Surg. 1993; 17:746-756. [PubMed: 8464095]

32. Row S, Peng HF, Schlaich EM, Andreadis ST, Swartz DD. Arterial implantation of tissue engineered blood vessels from mesenchymal stem cells in an ovine animal model. 2013 in preparation.

33. Koch S, Flanagan TC, Sachweh JS, Tanios F, Schnoering H, Deichmann T, Ella V, Kellomaki M, Gronloh N, Gries T, et al. Fibrin-polylactide-based tissue-engineered vascular graft in the arterial circulation. Biomaterials. 2010; 31:4731-4739. [PubMed: 20304484] 
34. Tillman BW, Yazdani SK, Neff LP, Corriere MA, Christ GJ, Soker S, Atala A, Geary RL, Yoo JJ. Bioengineered vascular access maintains structural integrity in response to arteriovenous flow and repeated needle puncture. J Vasc Surg. 2012; 56:783-793. [PubMed: 22917043]

35. Peirovi H, Rezvani N, Hajinasrollah M, Mohammadi SS, Niknejad H. Implantation of amniotic membrane as a vascular substitute in the external jugular vein of juvenile sheep. J Vasc Surg. 2012; 56:1098-1104. [PubMed: 22560305]

36. Cummings I, George S, Kelm J, Schmidt D, Emmert MY, Weber B, Zund G, Hoerstrup SP. Tissue-engineered vascular graft remodeling in a growing lamb model: expression of matrix metalloproteinases. Eur J Cardiothorac Surg. 2012; 41:167-172. [PubMed: 21530291]

37. Hoerstrup SP, Cummings Mrcs I, Lachat M, Schoen FJ, Jenni R, Leschka S, Neuenschwander S, Schmidt D, Mol A, Gunter C, et al. Functional growth in tissue-engineered living, vascular grafts: follow-up at 100 weeks in a large animal model. Circulation. 2006; 114:I159-166. [PubMed: 16820566]

**38. Quint C, Kondo Y, Manson RJ, Lawson JH, Dardik A, Niklason LE. Decellularized tissueengineered blood vessel as an arterial conduit. Proc Natl Acad Sci U S A. 2011; 108:9214-9219. Tissue engineered vascular grafts were rendered acellular and then implanted as interpositional grafts in the porcine carotid arteries demonstrating that allogeneic banked cells can be used for vascular regeneration in vivo. [PubMed: 21571635]

39. Robotin-Johnson MC, Swanson PE, Johnson DC, Schuessler RB, Cox JL. An experimental model of small intestinal submucosa as a growing vascular graft. J Thorac Cardiovasc Surg. 1998; 116:805-811. [PubMed: 9806387]

40. Watanabe M, Shin'oka T, Tohyama S, Hibino N, Konuma T, Matsumura G, Kosaka Y, Ishida T, Imai Y, Yamakawa M, et al. Tissue-engineered vascular autograft: inferior vena cava replacement in a dog model. Tissue Eng. 2001; 7:429-439. [PubMed: 11506732]

41. Zhou M, Liu Z, Liu C, Jiang X, Wei Z, Qiao W, Ran F, Wang W, Qiao T, Liu C. Tissue engineering of small-diameter vascular grafts by endothelial progenitor cells seeding heparincoated decellularized scaffolds. J Biomed Mater Res B Appl Biomater. 2012; 100:111-120. [PubMed: 22113845]

42. Cassel WS, Mason RA, Campbell R, Newton GB, Hui JC, Giron F. An animal model for smalldiameter arterial grafts. J Invest Surg. 1989; 2:181-186. [PubMed: 2487246]

43. Sparks SR, Tripathy U, Broudy A, Bergan JJ, Kumins NH, Owens EL. Small-caliber mesothelial cell-layered polytetraflouroethylene vascular grafts in New Zealand white rabbits. Ann Vasc Surg. 2002; 16:73-76. [PubMed: 11904808]

44. Chaouat M, Le Visage C, Autissier A, Chaubet F, Letourneur D. The evaluation of a smalldiameter polysaccharide-based arterial graft in rats. Biomaterials. 2006; 27:5546-5553. [PubMed: 16857256]

45. Hwang SJ, Kim SW, Choo SJ, Lee BW, Im IR, Yun HJ, Lee SK, Song H, Cho WC, Lee JW. The decellularized vascular allograft as an experimental platform for developing a biocompatible small-diameter graft conduit in a rat surgical model. Yonsei Med J. 2011; 52:227-233. [PubMed: 21319339]

46. Lopez-Soler RI, Brennan MP, Goyal A, Wang Y, Fong P, Tellides G, Sinusas A, Dardik A, Breuer C. Development of a mouse model for evaluation of small diameter vascular grafts. J Surg Res. 2007; 139:1-6. [PubMed: 17336332]

47. Hibino N, Yi T, Duncan DR, Rathore A, Dean E, Naito Y, Dardik A, Kyriakides T, Madri J, Pober JS, et al. A critical role for macrophages in neovessel formation and the development of stenosis in tissue-engineered vascular grafts. FASEB J. 2011

**48. Shin'oka T, Imai Y, Ikada Y. Transplantation of a tissue-engineered pulmonary artery. N Engl J Med. 2001; 344:532-533. First clinical trial of tissue-engineered grafts seeded with autologous bone marrow cells for the repair of congenital heart defects. [PubMed: 11221621]

**49. Shin'oka T, Matsumura G, Hibino N, Naito Y, Watanabe M, Konuma T, Sakamoto T, Nagatsu M, Kurosawa H. Midterm clinical result of tissue-engineered vascular autografts seeded with autologous bone marrow cells. J Thorac Cardiovasc Surg. 2005; 129:1330-1338. Follow up of the first clinical trial of tissue-engineered grafts seeded with autologous bone marrow cells for the repair of congenital heart defects. [PubMed: 15942574] 
50. Hibino N, McGillicuddy E, Matsumura G, Ichihara Y, Naito Y, Breuer C, Shinoka T. Late-term results of tissue-engineered vascular grafts in humans. Journal of Thoracic and Cardiovascular Surgery. 139:431-U233. [PubMed: 20106404]

51. L'Heureux N, McAllister TN, de la Fuente LM. Tissue-engineered blood vessel for adult arterial revascularization. N Engl J Med. 2007; 357:1451-1453. [PubMed: 17914054]

**52. McAllister TN, Maruszewski M, Garrido SA, Wystrychowski W, Dusserre N, Marini A, Zagalski K, Fiorillo A, Avila H, Manglano X, et al. Effectiveness of haemodialysis access with an autologous tissue-engineered vascular graft: a multicentre cohort study. Lancet. 2009; 373:1440-1446. Clinical results of tissue-engineered vascular grafts that were implanted as arteriovenous access grafts for haemodialysis in patients with end-stage renal disease. [PubMed: 19394535]

**53. Hibino N, McGillicuddy E, Matsumura G, Ichihara Y, Naito Y, Breuer C, Shinoka T. Late-term results of tissue-engineered vascular grafts in humans. J Thorac Cardiovasc Surg. 2010; 139:431436. 436e431-432. Late-term results of clinical trial using tissue-engineered vascular grafts that were implanted as cavopulmonary conduits in patients with single ventricle physiology. [PubMed: 20106404]

54. Shinoka T, Shum-Tim D, Ma PX, Tanel RE, Isogai N, Langer R, Vacanti JP, Mayer JE Jr. Creation of viable pulmonary artery autografts through tissue engineering. J Thorac Cardiovasc Surg. 1998; 115:536-545. discussion 545-536. [PubMed: 9535439]

55. Leyh RG, Wilhelmi M, Rebe P, Ciboutari S, Haverich A, Mertsching H. Tissue engineering of viable pulmonary arteries for surgical correction of congenital heart defects. Ann Thorac Surg. 2006; 81:1466-1470. discussion 1470-1461. [PubMed: 16564294]

56. Hashi CK, Zhu Y, Yang GY, Young WL, Hsiao BS, Wang K, Chu B, Li S. Antithrombogenic property of bone marrow mesenchymal stem cells in nanofibrous vascular grafts. Proc Natl Acad Sci U S A. 2007; 104:11915-11920. [PubMed: 17615237]

57. Brennan MP, Dardik A, Hibino N, Roh JD, Nelson GN, Papademitris X, Shinoka T, Breuer CK. Tissue-engineered vascular grafts demonstrate evidence of growth and development when implanted in a juvenile animal model. Ann Surg. 2008; 248:370-377. [PubMed: 18791357]

58. Cho SW, Kim IK, Kang JM, Song KW, Kim HS, Park CH, Yoo KJ, Kim BS. Evidence for in vivo growth potential and vascular remodeling of tissue-engineered artery. Tissue Eng Part A. 2009; 15:901-912. [PubMed: 18783324]

59. Nieponice A, Soletti L, Guan J, Hong Y, Gharaibeh B, Maul TM, Huard J, Wagner WR, Vorp DA. In vivo assessment of a tissue-engineered vascular graft combining a biodegradable elastomeric scaffold and muscle-derived stem cells in a rat model. Tissue Eng Part A. 2010; 16:1215-1223. [PubMed: 19895206]

60. Zhao Y, Zhang S, Zhou J, Wang J, Zhen M, Liu Y, Chen J, Qi Z. The development of a tissueengineered artery using decellularized scaffold and autologous ovine mesenchymal stem cells. Biomaterials. 2010; 31:296-307. [PubMed: 19819544]

61. Zhu B, Bailey SR, Elliott J, Li X, Escobar GP, Rodriguez EM, Agrawal CM. Development of a total atherosclerotic occlusion with cell-mediated calcium deposits in a rabbit femoral artery using tissue-engineering scaffolds. J Tissue Eng Regen Med. 2012; 6:193-204. [PubMed: 21400666]

62. Assmann A, Akhyari P, Delfs C, Flogel U, Jacoby C, Kamiya H, Lichtenberg A. Development of a growing rat model for the in vivo assessment of engineered aortic conduits. J Surg Res. 2012; 176:367-375. [PubMed: 22172135]

63. Janairo RR, Henry JJ, Lee BL, Hashi CK, Derugin N, Lee R, Li S. Heparin-modified smalldiameter nanofibrous vascular grafts. IEEE Trans Nanobioscience. 2012; 11:22-27. [PubMed: 22434651]

64. Akhmedov Sh D, Afanas'ev SA, Egorova MV, Andreev SL, Ivanov AV, Rogovskaia YV, Usov VY, Shvedov AN, Steinhoff G. Cell-free collagen-based scaffolds used for making blood vessels in cardiovascular surgery. Angiol Sosud Khir. 2012; 18:7-12. [PubMed: 22929664] 


\section{Highlights}

1. There is increasing demand for small diameter blood vessels as replacement grafts

2. Major roadblocks in engineered vascular grafts: cell sources and in vivo testing.

3. Clinical application of vascular grafts requires testing in relevant animal models 
BM-MSC, Ad-MSC, HF-

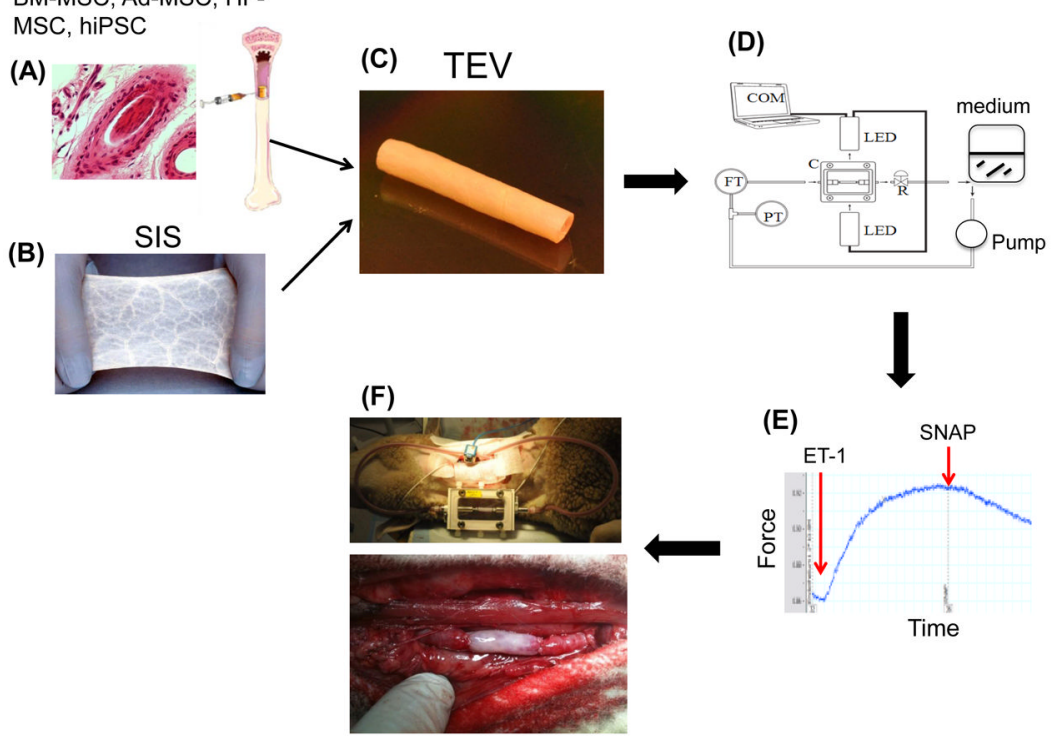

Figure 1. Stem cells, biomaterials and bioreactors for engineering vascular grafts

Adult mesenchymal stem cells (MSC) from various sources e.g. bone marrow (BM), adipose tissue (Ad), hair follicles (HF) or induced pluripotent stem cells (iPSC) have been used to engineer a functional vascular wall. Our group employed SIS in combination with fibrin glue to incorporate BM- or HF-MSC into the vascular wall of the cylindrical construct. After seeding the lumen with BM-derived endothelial cells, the TEVs were subjected to shear stress and pulsatile pressure using a dynamic bioreactor. Measurements of vascular contractility were used to evaluate the function of TEVs in response to vascular agonists such as endothelin- 1 (ET-1) and SNAP. After only two weeks in culture these TEVs were implanted into the arterial system of an ovine animal model where they remained patent for the duration of the experiment i.e. 3 months. 


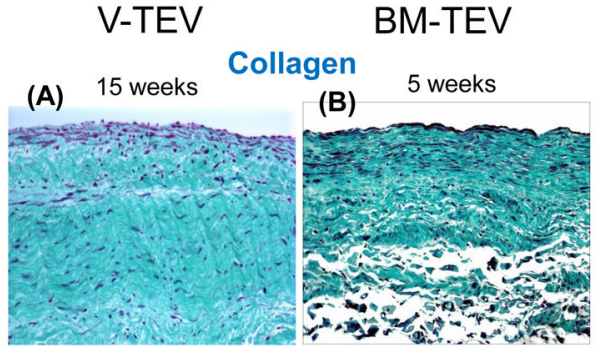

Elastin

(C)

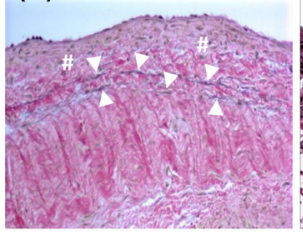

Swartz et al., Am. J. Physiol. (2005)
(D)

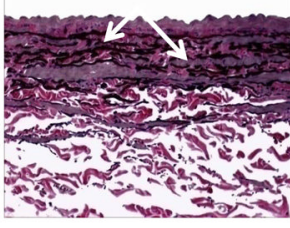

Liu et al., Cardiovasc Res. (2007)
qRT-PCR

(E)

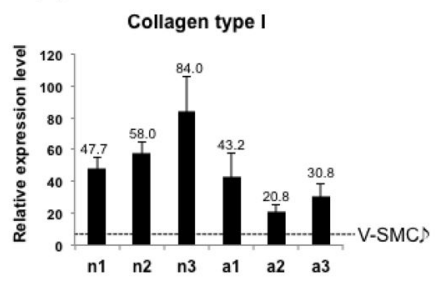

(F)

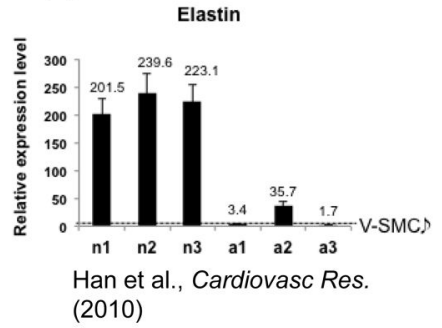

Figure 2. Remodeling of TEV after implantation

Fibrin-based TEV were prepared from vascular smooth muscle cells (V-TEV; A, C) that were isolated from saphenous veins or from BM-MSC derived SMC (BM-TEV; B, D) and implanted into the external jugular veins of 12-week old lambs. At the indicated times (15 or 5 weeks) the tissues were explanted and processed for histology. $(\mathbf{A}, \mathbf{B})$ Mason's trichrome showed abundant collagen (blue/green). (C, D) Verhoff's stain showed elastin fibers as black lines. Note the abundant expression and fibrillar organization of elastin (black lines) only in BM-TEV but not in V-TEV despite the longer implantation time of the later. Luminal surface is at the top of each panel and blood flows in the direction that crosses the plane of the page. (E, F) Quantitative RT-PCR for collagen (E) and elastin (F) expression in neonatal (n1-n3) BM-MSC, adult (a1-a3) BM-MSC or V-SMC. The data was normalized relative to GAPDH. The relative expression level was defined as the ratio of the normalized expression level of each gene in BM-SMC to that in V-SMC from umbilical veins of neonatal lambs. Note the difference in elastin expression between nBM-MSC, aBM-MSC and V-SMC. 
Table 1

Pre-clinical and clinical developments of Tissue-Engineered Vascular Grafts

\begin{tabular}{|c|c|c|c|c|}
\hline Species & Vascular graft/work & Site & Year & Ref. \\
\hline Human & $\begin{array}{l}\text { TEVs made of l-lactide and caprolactone scaffold and BMCs, transplanted } \\
\text { into cardiac vessels into pediatric patients; no failure up to } 32 \text { months. }\end{array}$ & Pulmonary cavo & $2001-2005$ & {$[53][49,54]$} \\
\hline Sheep & Fibrin-based TEVs with vascular ECs and SMCs was successfully implanted. & Jugular Vein & 2005 & [13] \\
\hline Sheep & $\begin{array}{l}\text { Decellularized ovine pulmonary arteries seeded with autologous ECs and } \\
\text { implanted. }\end{array}$ & Pulmonary artery & 2006 & {$[55]$} \\
\hline Sheep & $\begin{array}{l}\text { Ovine bone marrow progenitor cell-derived ECs and SMCs were seeded onto } \\
\text { SIS and implanted into an ovine animal model. The bone marrow-derived } \\
\text { TEVs demonstrated superior elastogenic potential. }\end{array}$ & Carotid artery & 2007 & {$[12]$} \\
\hline Rat & $\begin{array}{l}\text { Poly(L-lactic acid) nanofibrous scaffolds were seeded with BM-MSCs and } \\
\text { implanted. }\end{array}$ & Carotid artery & 2007 & {$[56]$} \\
\hline Human & $\begin{array}{l}\text { TEVs generated from autologous dermal fibroblasts and venous Ecs were } \\
\text { implanted in } 10 \text { patients for dialysis. }\end{array}$ & Arterio/Venous shunt & 2007 & {$[51]$} \\
\hline Sheep & $\begin{array}{l}\text { PGA scaffold coated with 1-lactide and epsilon-caprolactone seeded with } \\
\text { BM-MNCs and implanted. }\end{array}$ & Inferior venacava & 2008 & {$[57]$} \\
\hline Pig & $\begin{array}{l}\text { BM-MNCs were induced into ECs and SMCs in vitro, seeded onto porcine } \\
\text { decellularized aorta, and implanted. }\end{array}$ & Abdominal aorta & 2009 & {$[58]$} \\
\hline Rat & TEVs constructed with PEUU scaffolds seeded with MD-SCs and implanted. & Abdominal aorta & 2010 & {$[59]$} \\
\hline Sheep & $\begin{array}{l}\text { Fibrin-polylactide-based TEVs seeded with explanted Ecs and SMCs from } \\
\text { carotid artery and implanted. }\end{array}$ & Carotid artery & 2010 & [33] \\
\hline Sheep & $\begin{array}{l}\text { Autologous bone marrow cells seeded on decellularized arterial scaffold and } \\
\text { implanted in an ovine model. }\end{array}$ & Carotid artery & 2010 & {$[60]$} \\
\hline Human & $\begin{array}{l}\text { Autologous bone marrow cells were seeded on a biodegradeable PGA/ } \\
\text { eCaprolactone scaffold an implanted into single ventricle pediatric cases. }\end{array}$ & Cavo/pulmonary & $2001-2010$ & {$[53]$} \\
\hline Dog & $\begin{array}{l}\text { Canine smooth muscle cells seeded onto polyglycolic acid (PGA) scaffold. } \\
\text { Decellularized and seeded with canine EC. }\end{array}$ & Coronary/Peripheral & 2011 & {$[8]$} \\
\hline Pig & $\begin{array}{l}\text { Porcine cell seeded PGA scaffold. Decellularized, seeded with autologous EC } \\
\text { or EPC and implanted. }\end{array}$ & Carotid artery & 2011 & {$[38]$} \\
\hline Rabbit & $\begin{array}{l}\text { Establish a chronic total occlusion (CTO) model, atherosclerosis. Human } \\
\text { osteblast seeded on polycaprolactone (CPL) scaffold and implanted, observed } \\
\text { for occlusion. }\end{array}$ & Femoral artery & 2012 & {$[61]$} \\
\hline Rat & Decellularized rat aortic arches were implanted, with eight week follow up. & Infrarenal aorta & 2012 & {$[62]$} \\
\hline Rat & Heparin conjugated nanofiber matrix $(1 \mathrm{~mm})$ implanted. & Carotid artery & 2012 & {$[63]$} \\
\hline Dog & Canine decellularized arterial vessels implanted into arterial system. & Arterial & 2012 & {$[64]$} \\
\hline Dog & $\begin{array}{l}\text { Heparinized decellularized dog artery seeded with donor EPCs and } \\
\text { implanted. }\end{array}$ & Carotid artery & 2012 & [41] \\
\hline Sheep & $\begin{array}{l}\text { Decellularized arterial scaffolds seeded with autologous EPC. Assessed for } \\
\text { needle puncture and venous outflow. }\end{array}$ & Carotid/Jugular shunt & 2012 & {$[34]$} \\
\hline Sheep & $\begin{array}{l}\text { Autologous vascular cells seeded onto biodegradable PGA/P4HG. Followed } \\
\text { up to } 2 \text { years and monitored MMP expression. }\end{array}$ & Pulmonary artery & 2012 & {$[36]$} \\
\hline Sheep & $\begin{array}{l}\text { SIS-based TEVs with HF-MSC in the wall and BM-EC in the lumen where } \\
\text { connected in a arteriovenous loop to test short-term patency }\end{array}$ & Arteriovenous shunt & 2012 & [11] \\
\hline
\end{tabular}


Table 2

Animal models to study various aspects of TEV function

\begin{tabular}{|l|l|}
\hline TEV Study Feature & Animal Model \\
\hline Endothelialization & sheep \\
\hline Follow-up imaging & sheep/dog/rabbit/rat \\
\hline TEV growth & pig/sheep \\
\hline Patency & sheep \\
\hline Thrombogenicity & non-human primate/sheep \\
\hline Lipid metabolism/plaque formation & non-human primate/pig \\
\hline Matrix materials & rat/mice \\
\hline Cell infiltration into matrix & rat/mice \\
\hline Thrombogenicity-microvascular & rabbit \\
\hline Transgenic/gene manipulation & rabbit/rat/mice \\
\hline Intimal hyperplasia (IH) & rabbit \\
\hline Post-assessment (antibodies) & Non-human primate/dog/pig/rabbit/rat/mice \\
\hline
\end{tabular}

